\title{
NORMATIVE VERSUS ACTUAL METHODOLOGIES IN PLANNING RESEARCH: A HYBRID PICTURE
}

\begin{abstract}
What methodologies do we write about, and what type of research do we actually conduct and build upon in planning? Since the 80s planners have argued for more qualitative research within an interpretative paradigm. A content analysis of articles in Journal of Planning Education and Research do show a majority of qualitative studies, but cast within a pragmatic rather than an interpretative paradigm. More recently planners have reiterated the need for qualitative research, especially participatory and applied forms of research within a critical social science paradigm. Some recommendations for planning education and research are discussed.
\end{abstract}

\section{Keywords}

'Citation Impact'; 'Research Methodology'; 'Planning Education'; 'Planning Research’

\section{Authors}

Jacques du Toit, Department of Town and Regional Planning, University of Pretoria, Pretoria, South Africa

Nelius Boshoff, Centre for Research on Evaluation, Science and Technology (CREST) and DSTNRF Centre of Excellence in Scientometrics and Science, Technology and Innovation Policy (SciSTIP), Stellenbosch University, Stellenbosch, South Africa Niclesse Mariette, Department of Town and Regional Planning, University of Pretoria, Pretoria, South Africa 


\section{Corresponding Author}

Jacques du Toit; University of Pretoria, c/o Lynnwood Road \& Roper Street, Hatfield; South Africa

Email: jacques.dutoit@up.ac.za

\section{Biographical sketches}

Jacques du Toit is a Senior Lecturer in the Department of Town and Regional Planning, University of Pretoria, South Africa. His research interests include research methodology, planning methods and techniques, and environment-behavior studies.

Nelius Boshoff is a Senior Lecturer in the Centre for Research on Evaluation, Science and Technology (CREST) and a Senior Researcher in CREST and the Department of Science and Technology (DST) - National Research Foundation (NRF) Centre of Excellence in Scientometrics and Science, Technology and Innovation Policy (SciSTIP), Stellenbosch University, Stellenbosch, South Africa. His professional interests include studies of research utilization and the broader impacts of research, and bibliometrics with a focus on Africa.

Niclesse Mariette is an Assistant Lecturer in the Department of Town and Regional Planning, University of Pretoria, South Africa. His research interests include planning methods and techniques and urban design. 


\section{Acknowledgements}

The authors would like to thank the three reviewers whose comments served to improve the article.

\section{Unexplored Relationships in Planning Research}

As an applied social science, planning research faces two enduring questions with regard to methodology. Like the more descriptive social sciences, it faces the question of the relative merits of qualitative versus quantitative approaches. As an applied science, it faces the question of what knowledge we need to understand and intervene in human settlements, and by which methods to obtain such knowledge. While planning researchers have largely relied on the social sciences to deal with the first question, they sometimes deal with the second question through normative arguments for particular types of research having reflected on their experiences with planning (research). Normative arguments of course presuppose an 'ought to' with the intention of bringing about change. Thus, normative arguments for particular methodologies in planning research presuppose that we should have more of a certain type of research in planning and/or that a certain type of research should have a greater impact on planning.

While policy studies have yielded a substantial body of literature on the utilization of research, such studies pertain more to the extent to which decision-makers use research and whether academics and other types of researchers have been producing the 'right' knowledge to solve problems in the 'real' world. The focus of this article, however, is on critical or epistemic interests, and pertains to the methodologies we write about as opposed to the type of research we actually conduct and build upon in planning academia to advance our understanding of planning 
on a more fundamental level. This lesser explored aspect of planning scholarship is important, since it asks us to reflect on the significance of pursuing normative arguments for certain methodologies and the implications for training postgraduate students.

In this article, we (1) review normative arguments for different methodologies in planning research over a ten-year period from 1986 to 1995, (2) describe the subsequent extent (i.e., utilization) and citation impact (i.e., relevance) of actual methodologies featured in articles in the Journal of Planning Education and Research (JPER) over a ten-year period from 1996 to 2005, and (3) discuss recommendations for current planning education and research.

The article therefore provides a synthesis of normative arguments for different methodologies in planning research compared to a description of methodologies that have subsequently turned out to be applicable and relevant to planning research. Thus, it provides a critical reflection on two largely unexplored relationships in planning research, i.e., the relationship between ought and is - what type of research we ought to do in planning vs. what type of research we actually do in planning, and the relationship between the extent (the utilization of different methodologies) and citation impact (the relevance of different methodologies) - what type of research we do in planning vs. what type of research we build upon in planning.

Few studies have yet been conducted that considered the citation impact of planning research. Stevens (1990) looked at the role and importance of the social sciences in planning by examining both references in and citations to a core set of planning journals; concluding that planning had a firm 'alliance' with the social sciences, particularly geography and economics. Strathman (1992) 
examined the citation impact of articles in the Journal of Regional Science in terms of theory, method and empirical analysis, and pointed out an increase in theoretical research over time while flagging concerns over standards of scholarship. More recently, Suriñach et al. (2003) examined publication patterns in regional and urban studies to assess whether topics, techniques and applications have changed during the 1990s. They found a substantial increase in the application of quantitative techniques, with a greater variety of techniques used in regional as opposed to urban studies. As far as we are aware, no study has yet been conducted within planning that looks at both the extent and citation impact of different methodologies.

Several planning scholars however have criticized the use of citations to determine quality in planning scholarship. Although Stevens $(1990,341)$ reference two studies from the 1980s that found comparable results between impact factors and peer-ratings of journals in fields outside planning, Goldstein and Maier (2010) more recently conducted a survey amongst faculty in the Association of Collegiate Schools of Planning (ACSP) and found no correlation between impact factors and peer-ratings of various planning-related journals. Salet and Boer (2011) confirmed that a similar survey of theirs amongst European planning scholars also found no indicative correlation between impact factors and peer-ratings of various journals. Campbell (2011) in turn highlighted the negative implications of citation-based funding mechanisms such as the UKs Research Assessment Exercise for an applied field such as planning.

More specifically, criticisms mainly center on three issues, including (1) the often idiosyncratic nature of citations (i.e., the citing of articles for reasons other than relevance or importance), (2) the way in which journal impact factors are calculated and the inherent biases contained therein, 
and (3) the use of journal impact factors to determine tenure or funding. While we acknowledge these criticisms, we maintain that, with journal impact factors and any interpretation of quality aside, citations of individual articles can still serve as an indicator of the relevance of research within and beyond a particular field. Thus, our interpretation of citation impact here is limited to the relevance of particular methodologies, and not quality of scholarship. Simply put, qualitative articles are more-or-less likely to cite other qualitative articles on a particular theme, whether for reasons of praise or criticism. Moreover, reporting citation impact on an aggregate level mitigates some of the idiosyncratic effects of citation behavior within particular articles (e.g., see Stevens 1990, 341).

\section{Normative Arguments for Different Methodologies in Planning Research}

To identify normative arguments we looked for methodological articles in all planning related journals between 1986 and 1995 - a ten-year period prior to the ten-year period of research articles analyzed between 1996 and 2005. Although many research articles contain methodological reflections, we looked for articles that specifically argued for shifts towards particular methodologies on epistemological grounds. We therefore excluded textbooks as they are generally aimed at postgraduate students and tend to be more instructive rather than normative, as well as applied methodological articles that tend to discuss the application of particular methodologies within specific projects, but do not necessarily argue for methodological shifts on epistemological grounds. In addition, we were particularly interested in finding sets of articles that together form a normative discourse around certain methodologies. 
Following systematic and detailed keyword searches, we found only five articles that met our criteria. One article dates back to 1983 , but was nevertheless included since it fitted our criteria well and because our period of 1986 to 1995 served as an indicative delimitation only. While there are probably more articles that may have fitted our criteria, these would have been excluded if their normative inputs were tangential or concealed amongst other content. Although we obtained a small collection of articles, we nevertheless saw these five articles as a reasonable reflection of predominant arguments for different methodologies in planning research. All five articles argued for qualitative methodologies, some for field research or ethnography in particular, and, upon examining the citations amongst them, appear to form the type of discourse we were looking for. We briefly discuss the normative positions of each article in chronological order.

Lisa Peattie (1983) was arguably one of the first to draw attention to the need for a more critical social science paradigm with concomitant qualitative methods in planning research. Using housing as an example, she argued that large-scale quantitative projects in less-developed countries often served to conceal or protect vested interests. A focus on lived stories and underlying processes as a result of qualitative research was seen as bringing about new approaches to housing. Apart from Peattie, and to some extent Jacobs (1993), normative arguments for a more critical social science paradigm in planning research appear to wane until Bent Flyvbjerg $(2002 ; 2004)$ more than a decade later introduced the notion of 'phronetic planning research' (as will be discussed later on). Hemalata Dandekar early on also drew attention to qualitative methods, albeit in planning practice, in an article that appeared in JPER in 1986. Qualitative methods used in planning practice were identified and categorized into three 
categories to highlight their unique contribution to practice, including the study of (1) built form, (2) human interaction, and (3) planning processes and organizational structures (Dandekar 1986). Like Peattie, Dandekar also singled out the importance of qualitative methods to gauge planning processes.

John Gaber followed on from Dandekar to 'reassert' the importance of qualitative methods, this time more in relation to actual planning research over and above practice. Gaber argued that seminal field studies such as Jane Jacobs' Death and Life of Great American Cities and Herbert Gans’ Urban Villagers (1961 and 1982 respectively, as cited in Gaber 1993, 137) greatly enhanced our understanding of urban society. However, an overemphasis on quantitative methods led to a bias towards questions in planning research that could only be answered quantitatively, and that primary issues in planning that could only be captured qualitatively were being overlooked, including (1) the link between planning researchers and the people they plan for, (2) quality of life issues, and (3) informal/illegal activity (Gaber 1993, 140). While Gaber (1993: 138-40) highlighted the strengths of field (ethnographic) research to include (1) natural settings, (2) a contextual (holistic) approach, (3) a thick description of social reality, and (4) the capturing of processes of social reality, he nevertheless concluded that an epistemological compromise between qualitative and quantitative methods, by seeing them as complementary rather than competing, was preferable in planning research (Gaber 1993, 142-44). Again, the importance of using qualitative methods to gauge process was singled out, this time more in relation to social processes over and above planning processes. 
Clara Greed (1994) picked up on the application of ethnography to planning research and argued that it could also be applied to spatial research - a field generally associated with positivism and quantitative methods. Greed also argued that ethnography was furthermore useful in that it brought about a study of the planning 'tribe', i.e., research on planning/planners, to 'expose the values of the planning sub-culture' and to better understand how groups such as women relate to planning. Like Gaber, Greed also saw ethnography as complimentary to quantitative methods (Greed 1994, 133).

Around the same time as Gaber and Greed's writings, Jacobs, in an article titled The city unbound: Qualitative approaches to the city (1993), acknowledged the role of field research and ethnography in particular, but argued that shifts in social theory to post-structuralist and feminist thinking brought about methodological shifts within qualitative research to discursive and representational analyses in urban studies. On epistemological grounds, Jacobs argued for a shift towards interpretative social science, particularly social constructionism - seeing the city as 'socially-produced sites of meaning and power'. Concomitant qualitative methods include textual and narrative studies, particularly content/textual analysis, discourse/conversational analysis, as well as historiographies and biographies (see Table 1 later on). In the same article, Jacobs also reviewed a body of feminist work in urban studies (1993, 834-36), which, following Peattie (1983), reiterated the idea of a more critical over and above an interpretative paradigm for planning research.

To summarize; although our collection of articles was small, and no doubt that normative arguments for other types of methodologies may well have been made elsewhere, suffice to say 
Table 1: An index of designs applicable to planning research

\begin{tabular}{|c|c|c|}
\hline Research designs & Core logics & Subtypes \\
\hline Surveys & Generalization & $\begin{array}{l}\text { Cross-sectional surveys } \\
\text { Longitudinal surveys }\end{array}$ \\
\hline Experiments & Causal attribution & $\begin{array}{l}\text { True experiments (aka laboratory } \\
\text { experiments) } \\
\text { Quasi-experiments (aka } \\
\text { field/natural experiments) }\end{array}$ \\
\hline $\begin{array}{l}\text { Modeling, simulation, mapping and } \\
\text { visualization }\end{array}$ & Prediction/illustration & $\begin{array}{l}\text { Modelling; simulation } \\
\text { Mapping; visualization }\end{array}$ \\
\hline Textual and narrative studies & Interpretation (hermeneutical) & $\begin{array}{l}\text { Content/textual analysis } \\
\text { Discourse/conversational analysis } \\
\text { Historiography; biography }\end{array}$ \\
\hline Field studies & $\begin{array}{l}\text { Interpretation (ethnographical/ } \\
\text { phenomenological) }\end{array}$ & $\begin{array}{l}\text { Ethnography (aka participant } \\
\text { observation) } \\
\text { Phenomenology }\end{array}$ \\
\hline Case studies & Contextualization & $\begin{array}{l}\text { Single/multiple case studies } \\
\text { Comparative case studies }\end{array}$ \\
\hline Intervention research & Intervention & $\begin{array}{l}\text { Site/settlement analysis and } \\
\text { assessment } \\
\text { Plan/policy analysis and } \\
\text { assessment }\end{array}$ \\
\hline Evaluation research & Evaluation & $\begin{array}{l}\text { Diagnostic/clarification evaluation } \\
\text { (aka ex ante evaluation) } \\
\text { Implementation evaluation; } \\
\text { program monitoring } \\
\text { Outcome/impact evaluation (aka ex } \\
\text { post evaluation) }\end{array}$ \\
\hline Participatory action research (PAR) & Participation/action & $\begin{array}{l}\text { Technical/scientific/collaborative } \\
\text { PAR } \\
\text { Practical/mutual and/or } \\
\text { collaborative/deliberate PAR } \\
\text { Emancipating/enhancing/critical } \\
\text { science PAR }\end{array}$ \\
\hline $\begin{array}{l}\text { Meta-research } \\
\text { (Non-empirical studies) }\end{array}$ & $\begin{array}{l}\text { Various core logics depending on } \\
\text { the objectives of a study }\end{array}$ & $\begin{array}{l}\text { Literature reviews; research } \\
\text { synthesis } \\
\text { Conceptual analysis } \\
\text { Typology/model/theory } \\
\text { construction } \\
\text { Philosophical/normative/logical } \\
\text { argumentation }\end{array}$ \\
\hline
\end{tabular}

Source: Adapted from Du Toit and Mouton $(2012,128)$

Note: Intervention, evaluation and participatory action research may also be considered 'types' of research rather than standalone designs considering that each of them often combine different designs. E.g., an evaluation may well include both a survey and field research component. Still, these three types of research are considered standalone designs here due to their unique core logics. Thus, if the overall logic of a reported study was evidently one of evaluation, we would have coded its design as such irrespective of whether the study included different sub-designs. 
that the more predominant arguments around the mid-80s to mid-90s were mostly limited to qualitative methodologies in general and field research or ethnography in particular. Some attention was drawn to using ethnography in research on planning/planners in addition to research for planning, while textual and narrative methods were also singled out. It is important to note that, although discussions were limited to qualitative methods, such methods were argued on epistemological grounds, meaning that these methods were intended to advance interpretative and to a lesser extent critical social science research in planning and not just as an augmentation to or triangulation with quantitative methods.

\section{The Extent and Citation Impact of Actual Methodologies in JPER}

\section{Procedures}

We conducted a methodological content analysis of all full-length articles published in JPER between 1996 and 2005. JPER was purposefully selected as a reasonable representation or microcosm of planning research considering the following; (1) its wide focus that includes planning- theory, practice and pedagogy, (2) its interdisciplinary focus that encompasses disciplines closely associated with planning, including economics, geography, sociology, transportation, etc., and (3) its acceptance of both qualitative and quantitative studies as well as meta or theoretical studies. While Goldstein and Maier (2010) ranked JPER as the second most valued journal in their survey of faculty at ACSP schools, JPER is also arguably one of the more cited encompassing journals. Planning journals with impact factors higher than that of JPER (at least those listed under the categories 'Planning \& Development' or 'Urban Studies' as per Thomson Reuters' Journal Citation Reports) tend to be more specialized and thematically and methodologically narrower in scope. Still, we acknowledge that JPER is not completely 
representative of all planning research. Other social science-oriented journals such as Environment and Planning A, or more profession-oriented journals such as Journal of the American Planning Association, may well have yielded different methodological patterns.

The selection of the 1996 - 2005 period was also purposeful. Following the 1986 - 1995 period, we reasoned that authors between 1996 and 2005 should by then have taken cognizance of normative arguments in the broader planning literature from the previous decade. Like Strathman's (1992) study of the Journal of Regional Science, we furthermore opted for a 10-year period to ensure a sufficient sample of articles to analyze and to capture possible methodological shifts over time. Finally, we capped our sample as far back as 2005 to allow more recent articles enough time to gather comparable citations. Following the selection of JPER and the $1996-$ 2005 period, all full-length articles were sourced, excluding editorials, commentaries, book reviews, rejoinders, etc. - a total of 181 articles $(\mathrm{N}=181)$.

Of all the articles that included an empirical research component $(n=138)$, exactly half included a standalone methodology section, as opposed to about $38 \%$ that included a less-detailed discussion of methods elsewhere within the text or in footnotes, while the remaining $12 \%$ included no discussion at all. The large proportion (88\%) of empirical articles that did include some explication of methods allowed us to analyze articles with a reasonable degree of accuracy and consistency. We analyzed each article using a coding instrument that captured the methodologies of reported research in terms of four characteristics, including (1) empirical vs. non-empirical status, (2) predominant methodological approach (i.e., qualitative vs. quantitative), (3) predominant methodological paradigm (i.e., epistemology), and (4) overall research design. 
Considering that the first two characteristics were self-evident, we did not follow a two-person coding process to determine interrater reliability. However, to code different methodological paradigms systematically, we used Neuman's $(2011,119)$ tabular comparison of different social science paradigms as a framework. Our coding of different research designs in turn is synonymous with Du Toit and Mouton's (2012) typology of designs for social research in the built environment. Table 1 provides an index of 10 prototypical designs applicable to planning research together with their distinguishing core logics and associated subtypes.

Upon completion of the coding process, data were quantified and captured in IBM SPSS Statistics for further statistical analyses. We generated the necessary citation data in June 2014 by manually entering the titles of all 181 JPER articles into the online version of Thomson Reuters' Web of Science (WoS). The WoS, as part of its output, listed a citation score for each article by June 2014. By clicking on a citation score a full list of citing articles was displayed, which we then downloaded as a text based file. As a result we obtained a dataset that contained the full bibliographical details of each citing article for each of the 181 source articles. These were subsequently merged into a single Microsoft Excel file and exported to Microsoft Access for cleaning and the compilation of the following three citation indicators:

- Total number of citations (including self-citations): The total number of citations that an article received at the time of accessing WoS in June 2014. We considered citations in two document types, i.e., articles and reviews. Citations in all other document types such as editorials, commentaries, book reviews, etc., were excluded. 
- Total number of citations (excluding self-citations): Compiled as described above, but excluding self-citations. A self-citation occurred if a citing article and a cited article had at least one author name in common.

- Annual citation rate (excluding self-citations): Considering that articles ranged from 1996 to 2005, earlier articles would have had more chance to be cited than more recent articles. To compensate for this potential bias we compiled a time-based citation score. An annual citation rate was compiled for each article by dividing the number of citations an article received by June 2014 by the number of years since its publication.

In addition, we reported the three most citing journals for each of the categories in our analysis. As a matter of interest, we also established how many of the 181 source articles from 1996 to 2005 included a reference to any of the five normative articles we identified pre-1996. All five articles had in fact been cited. Of these, Peattie was the most cited author, cited by 13 of the 181 source articles. Dandekar and Jacobs in turn had been cited three times, while Gaber had been cited twice and Greed only once.

Tables $2-5$ show the extent of different types of studies in terms of the total number of times articles featuring such studies appeared between 1996 and 2005. The mean citation impact of different types of studies is shown in terms of the three indicators outlined above, together with the three most citing fields and the percentage of citations accounted for by each field. In each table we highlighted cells with the highest number and percentage of articles and highest mean citations (excluding self-citations). Tables $2-5$ show that mean citation figures excluding selfcitations are in all instances marginally lower than mean citation figures including self-citations. 
This suggests that JPER authors do not appear to cite themselves excessively, and that concerns in the literature about self-citing behavior are less warranted here.

\section{The Extent and Citation Impact of Empirical vs. Non-empirical Studies}

We first present a split between empirical vs. non-empirical studies considering that the next three subsections deal with empirical studies only. Table 2 shows the extent and citation impact of empirical vs. non-empirical studies in JPER between 1996 and 2005.

About $70 \%$ of all the 181 full-length articles published in JPER between 1996 and 2005 reported empirical research, while about $24 \%$ of articles were non-empirical with the remainder having included an equally substantive empirical and non-empirical component. Mean citation figures (excluding self-citations) of the latter are noticeably higher compared to those for pure empirical or non-empirical articles, although the high standard deviation (23.6) suggests the presence of one or more outliers. Irrespective of empirical status, the impact of JPER articles appears to have been largely contained within the broader field of planning, given that JPER and the Journal of the American Planning Association were the first and second most citing journals respectively in each category.

Although the normative arguments discussed earlier were all about empirical research, we see the almost a quarter of non-empirical work in JPER as encouraging. Such work, as per Table 1, would have included standalone literature reviews, research syntheses, conceptual analyses, typology/model/theory construction, normative argumentation, etc. All these offer a critical reflection on the state of empirical work in a field and provide building blocks for subsequent 
Table 2: The extent and citation impact of empirical vs. non-empirical studies in JPER between 1996 and 2005

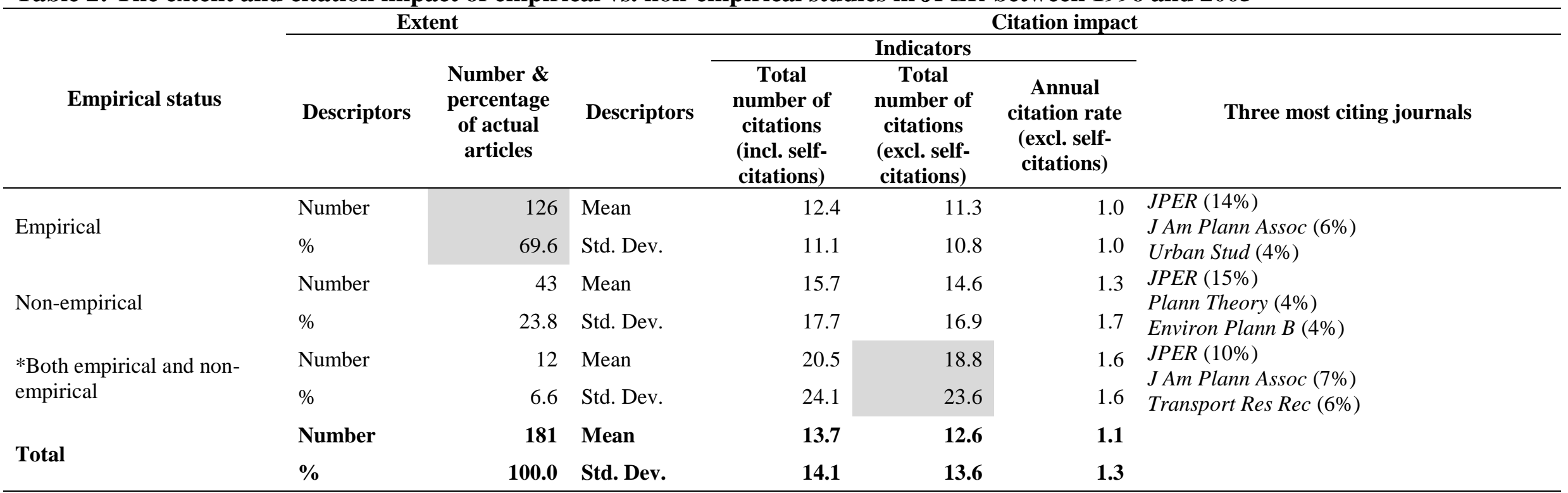

Note: *Dual articles that included an empirical (research) component as well as a separate but equally substantive non-empirical component in which additional questions of metaconcern are addressed. 
empirical work. A dialectic between empirical and a substantive body of non-empirical work is certainly necessary in a social science-oriented field such as planning in which different theories and methods often contend. We hereafter focus on the subset of empirical articles $(n=138)$ only.

\section{The Extent and Citation Impact of Different Methodological Approaches}

In this article, the term 'methodological approach' refers to whether a particular study was predominantly either qualitative or quantitative in terms of the type of data that were collected. The use of the term 'methodological approach' in terms of a qualitative/quantitative dichotomy with regard to the type of data that were collected is widely used in the social sciences (e.g., see Creswell, 2009 and Neuman, 2011). While a different interpretation of the qualitative/quantitative dichotomy in terms of the use of different measurement scales is also possible, this article adopts the broader interpretation more generally used in the social sciences. Table 3 shows the extent and citation impact of different methodological approaches in JPER between 1996 and 2005.

Consistent with normative arguments for qualitative research, more than half of all articles featuring empirical research were in fact predominantly qualitative in terms of design and data. Considering the bulk of qualitative research, and assuming that qualitative articles are more likely to cite other qualitative articles, one may expect mean citation figures for qualitative studies to be higher compared to those for other types of studies. However, mean citation figures for quantitative articles are in fact noticeably higher compared to those for qualitative articles. Thus, we see a discrepancy between the extent and citation impact of qualitative vs. quantitative research in JPER. Three possible reasons should be kept in mind here. Firstly, it is arguably 
Table 3: The extent and citation impact of different methodological approaches in JPER between 1996 and 2005

\begin{tabular}{|c|c|c|c|c|c|c|c|}
\hline \multirow[b]{3}{*}{ Methodological approaches } & \multicolumn{3}{|c|}{ Extent } & \multicolumn{3}{|c|}{ Citation impact } & \multirow[b]{3}{*}{ Three most citing journals } \\
\hline & \multirow[b]{2}{*}{ Descriptors } & \multirow[b]{2}{*}{$\begin{array}{c}\text { Number \& } \\
\text { percentage } \\
\text { of actual } \\
\text { articles }\end{array}$} & \multirow[b]{2}{*}{ Descriptors } & \multicolumn{3}{|c|}{ Indicators } & \\
\hline & & & & $\begin{array}{c}\text { Total } \\
\text { number of } \\
\text { citations } \\
\text { (incl. self- } \\
\text { citations) }\end{array}$ & $\begin{array}{c}\text { Total } \\
\text { number of } \\
\text { citations } \\
\text { (excl. self- } \\
\text { citations) }\end{array}$ & $\begin{array}{l}\text { Annual } \\
\text { citation rate } \\
\text { (excl. self- } \\
\text { citations) }\end{array}$ & \\
\hline \multirow{2}{*}{ Quantitative } & Number & 47 & Mean & 16.6 & 15.3 & 1.4 & \multirow{6}{*}{$\begin{array}{l}\text { JPER }(11 \%) \\
\text { J Am Plann Assoc }(7 \%) \\
\text { Urban Stud }(7 \%) \\
\text { JPER }(16 \%) \\
\text { J Am Plann Assoc }(5 \%) \\
\text { Plann Theory }(3 \%) \\
\text { JPER }(12 \%) \\
\text { J Am Plann Assoc }(6 \%) \\
\text { Transport Res Rec }(6 \%)\end{array}$} \\
\hline & $\%$ & 34.1 & Std. Dev. & 12.5 & 12.0 & 1.1 & \\
\hline \multirow{2}{*}{ Qualitative } & Number & 74 & Mean & 10.5 & 9.6 & .9 & \\
\hline & $\%$ & 53.6 & Std. Dev. & 10.1 & 9.8 & 1.0 & \\
\hline \multirow{2}{*}{$\begin{array}{l}\text { *Both quantitative and } \\
\text { qualitative }\end{array}$} & Number & 17 & Mean & 14.6 & 13.1 & 1.1 & \\
\hline & $\%$ & 12.3 & Std. Dev. & 20.8 & 20.3 & 1.3 & \\
\hline \multirow{2}{*}{ Total } & Number & 138 & Mean & 13.1 & 12.0 & 1.1 & \\
\hline & $\%$ & 100.0 & Std. Dev. & 12.9 & 12.4 & 1.1 & \\
\hline
\end{tabular}

Note: *Articles that included both quantitative and qualitative data, but not necessarily in a 'mixed-method' sense. The latter refers to the integration of quantitative and qualitative data through either 'within-method triangulation' or 'between-method triangulation' (e.g., see Gaber and Gaber 2004, 228; Creswell 2009, 4). No article contained data that were considered truly mixed. 
normal scientific practice for quantitative research to be cited more due to its deductive nature and relative generalizability of research findings. Qualitative studies featuring highly unique or contextualized cases may not always appear relevant even to other qualitative researchers.

Secondly, quantitative research tends to be closer to planning practice, a fairly large field, whereas qualitative research tends to be closer to planning theory, a much smaller field. Thirdly, quantitative articles in JPER on average had more authors compared to qualitative articles (1.9 versus 1.3 authors; the average number of authors for articles that included both quantitative and qualitative data was 1.7$)$. More authors per article imply a larger number of scholars in the immediate network of authors, and consequently a larger number of scholars that could cite an article. Still, considering normative arguments for planning scholars to take qualitative research more seriously and the subsequent extent of qualitative work, one may have expected citation figures between qualitative and quantitative articles to be more evenly distributed. Clearly, they are not.

\section{The Extent and Citation Impact of Different Methodological Paradigms}

Recall that normative arguments for qualitative methodologies were also on epistemological grounds, meaning that qualitative studies ought to have been conducted in an interpretative and to a lesser extent critical social science paradigm. Table 4 shows the extent and citation impact of different methodological paradigms in JPER between 1996 and 2005.

The bulk of empirical articles (about 61\%) were predominantly pragmatic on epistemological grounds, followed by critical social science studies (about 19\%) and post-positivist studies (about 17\%). Pragmatic studies were predominantly qualitative and/or quantitative, with the 
Table 4: The extent and citation impact of different methodological paradigms in JPER between 1996 and 2005

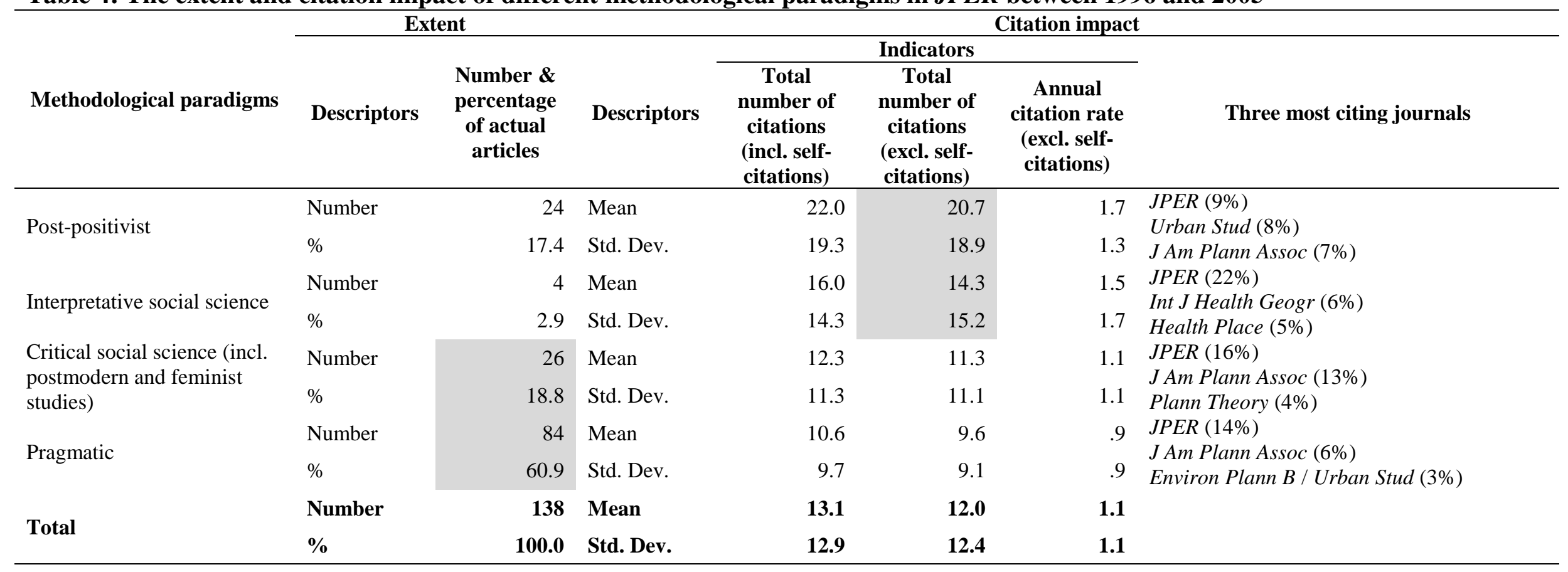


research question and interpretation of data primarily of a problem-solving nature rather than for purposes of establishing knowledge on explicitly post-positivist, interpretative or critical social science grounds. Thus, despite normative arguments for a stronger interpretative knowledge base in planning, and although more than half of all empirical articles were predominantly qualitative, only four studies (about 3\% of all empirical studies) could be considered truly interpretative on epistemological grounds. This means that the widespread use of qualitative methods in planning research was arguably for reasons other than epistemological, and might reflect a range of possible reasons, including a lack of quantitative research skills or the use of qualitative methods such as interviews for mere fact-finding purposes. A similar review of evaluations of estate renewals in Australia also revealed extensive use of interviews and focus groups, but almost no use of proper ethnographic or participatory action research (Maginn 2006, 13).

We also see a discrepancy here between the extent and citation impact of different paradigms, with post-positivist and interpretative studies showing noticeably higher mean citation figures, especially compared to pragmatic studies that showed the lowest. Thus, interpretative studies, although very limited, certainly showed their impact in terms of citations, not just within planning, but also beyond in the health-related fields covered by the International Journal of Health Geographics and Health \& Place. Again, it could be normal scientific practice for articles in which there is a greater coherence between epistemology and concomitant methods to be cited more due to a clearer theoretical contribution. Alternatively, it could also be that normative arguments for a stronger interpretative knowledge base may have influenced the research we choose to cite over and above the research we actually do. 


\section{The Extent and Citation Impact of Different Research Designs}

Recall that normative arguments for qualitative methodologies singled out field research and ethnography in particular, and to some extent textual and narrative studies. Table 5 shows the extent and citation impact of different research designs in JPER between 1996 and 2005.

Table 5 foremost shows that planning researchers use a wide range of designs, albeit to a different extent. The three most utilized designs include case studies (more than a third of all empirical studies), surveys (about 18\%) and, interestingly, evaluation research (about 17\%). Evaluation research, like intervention research, is an applied form of research that is usually intended for a practitioner rather than an academic audience. Field studies were very few in number - only five in total (all five based on ethnography with no phenomenological studies), while textual and narrative studies were double that of field studies. As can be expected, we again see a discrepancy between the extent and citation impact of different designs, with the three most utilized designs differing from the three most cited designs. The most cited research include modelling (partially due to transportation studies as is evident from the title of the second most citing journal, Transportation Research Record), followed by experiments (although there were only three in number), and then, interestingly, field studies. Thus, although field studies were limited considering the costs and ethical implications of being in the field, their impact is certainly seen in terms of citations within planning-related fields, lending some credence to normative arguments for field studies and ethnographies. Textual and narrative studies however were the second least cited type of research. 
Table 5: The extent and citation impact of different research designs in JPER between 1996 and 2005

\begin{tabular}{|c|c|c|c|c|c|c|c|}
\hline \multirow{3}{*}{ Research designs } & \multicolumn{3}{|c|}{ Extent } & \multicolumn{4}{|c|}{ Citation impact } \\
\hline & \multirow[b]{2}{*}{ Descriptors } & \multirow[b]{2}{*}{$\begin{array}{c}\text { Number \& } \\
\text { percentage } \\
\text { of actual } \\
\text { articles }\end{array}$} & \multirow[b]{2}{*}{ Descriptors } & \multicolumn{3}{|c|}{ Indicators } & \multirow[b]{2}{*}{ Three most citing journals } \\
\hline & & & & $\begin{array}{c}\text { Total } \\
\text { number of } \\
\text { citations } \\
\text { (incl. self- } \\
\text { citations) }\end{array}$ & $\begin{array}{c}\text { Total } \\
\text { number of } \\
\text { citations } \\
\text { (excl. self- } \\
\text { citations) }\end{array}$ & $\begin{array}{l}\text { Annual } \\
\text { citation } \\
\text { rate (excl. } \\
\text { self- } \\
\text { citations) }\end{array}$ & \\
\hline \multirow{2}{*}{ Surveys } & Number & 21 & Mean & 11.3 & 10.4 & 1.0 & JPER (14\%) \\
\hline & $\%$ & 17.6 & Std. Dev. & 9.9 & 9.3 & .9 & J Am Plann Assoc $(8 \%)$ \\
\hline \multirow[b]{2}{*}{ Experiments } & Number & 3 & Mean & 20.3 & 19.0 & 1.8 & $\operatorname{JPER}(16 \%)$ \\
\hline & $\%$ & 2.5 & Std. Dev. & 9.5 & 10.5 & .9 & Landscape Urban Plan (8\%) \\
\hline \multirow{2}{*}{$\begin{array}{l}\text { Modelling, simulation, } \\
\text { mapping, and visualization }\end{array}$} & Number & 12 & Mean & 22.8 & 21.7 & 1.9 & Urban Stud $(10 \%)$ \\
\hline & $\%$ & 101 & Std Dey & 153 & 148 & 13 & Transport Res Rec (8\%) \\
\hline \multirow{3}{*}{ Textual and narrative studies } & Number & 10 & Mean & 4.6 & 4.0 & 3 & JPER $(26 \%)$ \\
\hline & & & & & & & $J$ Am Plann Assoc (15\%) \\
\hline & $\%$ & 8.4 & Std. Dev. & 2.7 & 2.7 & .2 & Urban Geogr / Transp Policy / Prog Plann (4\%) \\
\hline \multirow[b]{2}{*}{ Field studies } & Number & 5 & Mean & 16.8 & 15.6 & 1.3 & $\operatorname{JPER}(23 \%)$ \\
\hline & $\%$ & 4.2 & Std. Dev. & 10.6 & 11.0 & .7 & $\begin{array}{l}\text { J Am Plann Assoc (5\%) } \\
\text { Soc Sc Med / Environ Plann A / Plann Theorv (4\%) }\end{array}$ \\
\hline \multirow[b]{2}{*}{ Case studies } & Number & 40 & Mean & 11.3 & 10.4 & 1.0 & $\operatorname{JPER}(14 \%)$ \\
\hline & $\%$ & 33.6 & Std. Dev. & 10.4 & 10.0 & 1.0 & $\begin{array}{l}\text { J Am Plann Assoc }(4 \%) \\
\text { Environ Plann A }(4 \%)\end{array}$ \\
\hline \multirow{2}{*}{ Intervention research } & Number & 1 & Mean & 3.0 & 3.0 & .3 & JPER $(67 \%)$ \\
\hline & $\%$ & .8 & Std. Dev. & N/A & N/A & N/A & Urban Stud $(33 \%)$ \\
\hline \multirow{2}{*}{ Evaluation research } & Number & 20 & Mean & 12.4 & 10.7 & 1.0 & $\operatorname{JPER}(11 \%)$ \\
\hline & $\%$ & 16.8 & Std. Dev. & 10.2 & 9.6 & .9 & $\begin{array}{l}J \text { Am Plann Assoc }(6 \%) \\
\text { JPlan Lit }(6 \%)\end{array}$ \\
\hline \multirow[b]{2}{*}{ Participatory action research } & Number & 7 & Mean & 13.3 & 12.7 & 1.3 & $\operatorname{JPER}(12 \%)$ \\
\hline & $\%$ & 5.9 & Std. Dev. & 13.2 & 12.7 & 1.3 & $\begin{array}{l}\text { Agr Hum Values (5\%) } \\
\end{array}$ \\
\hline \multirow{2}{*}{ Total } & Number & 119 & Mean & 12.6 & 11.6 & 1.1 & \\
\hline & $\%$ & 100.0 & Std. Dev. & 11.2 & 10.8 & 1.0 & \\
\hline
\end{tabular}

Note: Articles that reported research featuring more than one design are excluded to avoid conflation within citation figures. Consequently the total number of 119 articles reported here is lower compared to the total of 138 articles in Tables 3 and 4. 
Caution should however be exercised when extrapolating from the small numbers of articles in Table 5. Caution here is also warranted by the relative uniformity of citation counts across the different design categories after controlling for publication age (annual citation rate) as well as the small average number of citations regardless of category.

\section{Recommendations for Planning Education and Research}

In this article we reviewed normative arguments for different methodologies in planning research and described the subsequent extent and citation impact of actual methodologies in JPER.

Normative arguments were mostly limited to qualitative methodologies and field research or ethnography in particular, and to some extent textual and narrative studies. Normative arguments for qualitative methodologies were also intended to advance interpretative and to a lesser extent critical social science research in planning. We found that although more than half of the studies we analyzed were in fact predominantly qualitative, the citation impact of predominantly quantitative studies was noticeably higher. Moreover, the bulk of qualitative studies were not cast within an interpretative paradigm, but within a pragmatic and to a lesser extent critical social science paradigm. Yet, the handful of qualitative studies that were truly interpretative had a much greater citation impact compared to those that were pragmatic or critical in orientation. Consequently we have a hybrid picture regarding the relationship between ought and is - what type of research we ought to do in planning vs. what type of research we actually do in planning, as well as the relationship between extent and impact - what type of research we do in planning vs. what type of research we build upon in planning. 
Is such a hybrid picture a bad thing? Not necessarily, since we cannot presume that because we put forward normative arguments to have more of a certain type of research in planning that we should necessarily see this in subsequent research. Moreover, we reported only one case journal here, while there are arguably several other factors that could also have contributed to the methodological profiles reported here. What is important is to acknowledge that, as with planning practice, what we argue for and how things turn out in actual planning research is not necessarily similar or neatly correlated, and that we need to ask further questions about the relationships between the grounds for, extent, and impact of different methodologies in planning research. Future research may for example include a similar methodological content analysis of all articles referenced in the 181 JPER articles, as well as of articles citing the JPER articles. Such an analysis could distinguish between planning research and non-planning research in both the referenced and citing articles. In doing so, one would be able to draw firmer conclusions regarding the extent to which planning research is informed by normative arguments both from within and outside its own discipline, as well as the extent to which normative arguments in planning research are informing its own and other disciplines. We therefore regard this hybrid picture as normal, but nevertheless discuss two recommendations for current planning education and research.

Firstly, there is arguably a need for greater methodological coherence in planning research, i.e., there should as far as possible be a logical coherence between epistemology and concomitant methods. Du Toit and Mouton's $(2012,132)$ typology for example outlines each of the designs in Table 1 in relation to their concomitant methodological characteristics. Using this typology, field studies should for example be predominantly exploratory/descriptive and conducted within an 
interpretative paradigm. Not only did our results show that field studies that were truly interpretative had a greater citation impact compared to other qualitative studies, but the more methodologically coherent studies are the more they are likely to be defendable (e.g., see Night and Turnbull 2008, 73), and the more likely they are to 'sustain scholarly conversations' (e.g., see Hopkins 2001, 399). Yet, the applied and often messy nature of planning studies makes it difficult to cast projects within a purely post-positivist, interpretative, or critical paradigm, while pragmatism will often be a compromise.

Secondly, postgraduate students in planning should be exposed to epistemology to the same extent as their counterparts in the social sciences. While Goldstein (2012) made several suggestions regarding the improvement of doctoral education in US planning schools, we may add that at least basic epistemology, in particular how the main paradigms are associated with different research designs, should be included in curricula. Considering this, we conducted a similar review of methodological articles published since 2000 and identified the following:

Qualitative methodologies are still on the agenda (e.g., see Dandekar, 2005), but perhaps with less emphasis on field research and ethnography and more on discourse analysis and fourth generation (qualitative) evaluation following successes with these methods in housing studies (e.g., see Maginn's (2006) introduction to a special issue on qualitative methods in Urban Policy and Research). Flyvbjerg's (2002; 2004) notion of 'phronetic planning research' is highly pragmatic with regard to methods, but its intention to have a definite influence on planning outcomes is certainly suggestive of a very specific form of participatory action research (even to the extent of involving mass media) and especially a critical social science orientation (e.g., 'who 
gains and by what means?'). Lake and Zitcer (2012) advocate a more grassroots form of participatory action research by involving people in the actual authorship of planning research. The JPER more recently featured a symposium on the relationship between planning research and practice, highlighting the role of applied or more involved forms of research, such as intervention, evaluation and participatory action research (e.g., see Wu and Brooks' (2012) introduction to this symposium, and especially Forsyth's (2012) discussion of different cultures in planning research).

Our findings however showed that discourse analysis and intervention and participatory action research were as yet very limited in JPER by 2005 . Questions therefore arise about the current extent of these types of studies and whether their results are perhaps not best reported in policy and practitioner outlets rather than scholarly journals. Indeed, such applied forms of research, especially participatory action research, pose many challenges for traditional methodology courses and for conducting research within the confines of academia, some of which are addressed in the JPER symposium.

\section{References}

Campbell, Heather. 2011. Commentary: Bibliometrics - The science of measuring anything and knowing the quality of little. Journal of Planning Education and Research 31 (1): 101102.

Creswell, John W. 2009. Research design: Qualitative, quantitative, and mixed-methods approaches. Los Angeles: Sage. 
Dandekar, Hemalata C. 1986. Some uses and potentials of qualitative research in planning. Journal of Planning Education and Research 6 (1): 42-49.

Dandekar, Hemalata C. 2005. Qualitative methods in planning research and practice. Journal of Architectural and Planning Research 22 (2): 129-37.

Du Toit, Jacques L., and Johann Mouton. 2012. A typology of designs for social research in the built environment. International Journal of Social Research Methodology 16 (2): 125-39.

Flyvbjerg, Bent. 2002. Bringing power to planning research: One researcher's praxis story. Journal of Planning Education and Research 21: 353-66.

Flyvbjerg, Bent. 2004. Phronetic planning research: Theoretical and methodological reflections. Planning Theory \& Practice 5 (3): 283-306.

Forsyth, Ann. 2012. Commentary: Alternative cultures in planning research - From extending scientific frontiers to exploring enduring questions. Journal of Planning Education and Research 32 (2): 160-68.

Gaber, John. 1993. Reasserting the importance of qualitative methods in planning. Landscape and Urban Planning 26: 137-48.

Gaber, John, and Sharon Gaber. 2004. If you could see what I know: Moving planners' use of photographic images from illustrations to empirical data. Journal of Architectural and Planning Research 21(3): 222-38.

Goldstein, Harvey A. 2012. The quality of planning scholarship and doctoral education. Journal of Planning Education and Research 32 (4): 493-96.

Goldstein, Harvey, and Gunther Maier. 2010. The use and valuation of journals in planning scholarship: Peer assessment versus impact factors. Journal of Planning Education and Research 30 (1): 66-75. 
Greed, Clara. 1994. The place of ethnography in planning: Or is it 'real research'? Planning Practice \& Research 9 (2): 119-28.

Hopkins, Lewis D. 2001. Planning as science: Engaging disagreement. Journal of Planning Education and Research 20: 399-406.

Jacobs, Jane M. 1993. The city unbound: Qualitative approaches to the city. Urban Studies 30 (4/5): 827-48.

Lake, Robert W., and Andrew W. Zitcer. 2012. Who says? Authority, voice, and authorship in narratives of planning research. Journal of Planning Education and Research 32 (4): 389-99.

Maginn, Paul J. 2006. Urban policy analysis through a qualitative lens: Overview to special issue. Urban Policy and Research 24 (1): 1-15.

Neuman, W. Lawrence. 2011. Social research methods: Qualitative and quantitative approaches. Boston: Pearson.

Night, Andrew, and Neil Turnbull. 2008. Epistemology. In Advanced research methods in the built environment, edited by Andrew Knight and Les Ruddock, 64-74. Oxford: WileyBlackwell.

Peattie, Lisa. 1983. Realistic planning and qualitative research. Habitat International 7 (5/6): 227-34.

Salet, Willem, and Rene Boer. 2011. Commentary: Comparing the use and valuation of journals between U.S. and European planning scholars. Journal of Planning Education and Research 31 (1): 95-97.

Stevens, Garry. 1990. An alliance confirmed: Planning literature and the social sciences. Journal of the American Planning Association 56 (3): 341-49. 
Strathman, James G. 1992. Analysis of theoretical, methodological and empirical research in the Journal of Regional Science. Journal of Regional Science 32 (4): 501-9.

Suriñach, J., J.C. Duque, R. Ramos, and V. Royuela. 2003. Publication patterns in regional and urban analysis: Have topics, techniques and applications changed during the 1990s? Regional Studies 37 (4): 351-63.

Wu, Weiping, and Michael Brooks. 2012. The engagement of planning scholarship with practice: Brief introduction to symposium. Journal of Planning Education and Research 32 (2): 133-34. 